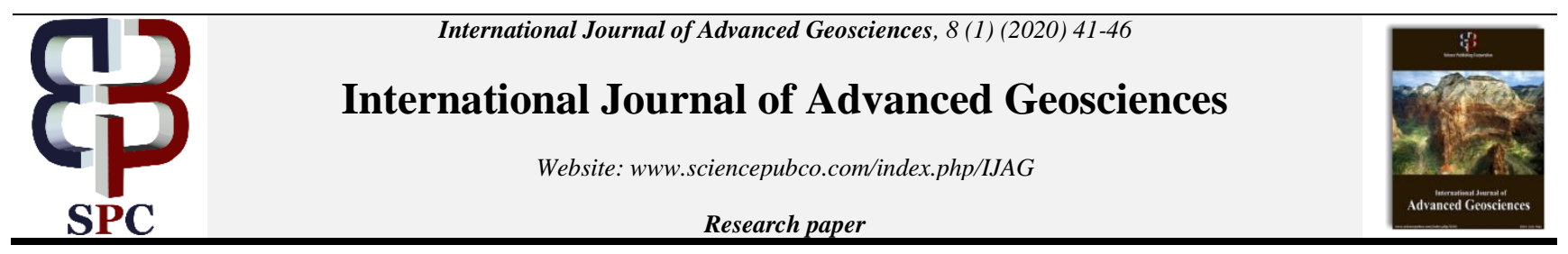

\title{
A study on the effects of groundnut shell ash on strength characteristics of soil
}

\author{
M. O. Ajala ${ }^{1}$, K. J. Akinyede ${ }^{1}$, G. O. Adunoye ${ }^{1 *}$, I. J. Akintola ${ }^{1}$ \\ ${ }^{1}$ Department of Civil Engineering, Obafemi Awolowo University, Ile-Ife, Nigeria \\ *Corresponding author E-mail: kayadunoye@yahoo.com
}

\begin{abstract}
This study investigated the effect of groundnut shell ash (GSA) on the strength of selected lateritic soils, with a view to determining the optimum percentage of GSA that will give the best strength properties of the soils. Soil samples were collected from two different borrow pits and identified as sample A and sample B respectively. Preliminary tests (Natural moisture content, specific gravity, grain size analysis, Atterberg limit) and engineering tests (compaction and unsoaked California bearing ratio (CBR)) were conducted on the soil samples in their natural state. GSA was then added to the soils at $2 \%, 4 \%$ and $6 \%$ proportions. Atterberg limits, compaction and unsoaked CBR tests were conducted for each addition of GSA. The results showed that there was much improvement in the properties of the soils, with values of plasticity index (PI) reducing from $23.02 \%$ (at $0 \% \mathrm{GSA}$ ) to $12.55 \%$ (at $6 \% \mathrm{GSA}$ ) for sample A; and $35.14 \%$ (at $0 \%$ GSA) to $2 . .54 \%$ (at $6 \% \mathrm{GSA}$ ) for sample B. It was also observed that addition of GSA generally caused reduction in optimum moisture content (OMC) with an increase in corresponding maximum dry density (MDD). For sample A the maximum value of unsoaked CBR (17\%) was obtained at $2 \%$ GSA, while for sample B, maximum CBR value (4\%) was obtained at $4 \%$ GSA. It was concluded that GSA could be used to significantly improve the strength of lateritic soil.
\end{abstract}

Keywords: Atterberg Limits; California Bearing Ratio; Groundnut Shell; Stabilisation Strength Characteristics.

\section{Introduction}

The importance of soil in civil engineering construction cannot be over-emphasised. The stability of any structure depends on the strength and geotechnical properties of such soils. In handling expansive or problem soils (i.e. soils with poor properties), civil engineers are faced with the option of either using the soil and increase the cost of construction or improve the properties of the expansive soil. However, since it is more economical to improve the properties of the soil, soil stabilisation is often engaged (Adetoro and Dada 2015).

Different methods of soil stabilisation or improvement have been used and are still be utilised. Many researchers have explored and adopted different stabilisation methods, most of which involve the use of industrial stabilising agents such as cement, lime, etc. Muntohar (1999) investigated the effect of fly ash and pozzolanic material on soil improvement. Moreover, studies have shown that pozzolanic materials coupled with rice husk ash was a potential material for soil improvement (Muntohar 1999). Alabadan et al. (2006) reported that organic materials had been turned into ashes (through a process referred to as thermal decomposition) for soil improvement. The ash produced was ground to a fine size and mixed with lime in order to increase the engineering properties of the lateritic soil. According to James and Rao (1986), the quality of this stabilising agent depends on burning time, temperature, cooling time and grinding conditions.

Groundnut shell is an agricultural waste obtained from milling of groundnut. In Nigeria, groundnut is highly cultivated in the north and north-central region and contributes about $7 \%$ to the world groundnut production, which makes Nigeria the third largest producer of groundnut in the world (Oriola and Moses 2010; Edeh et al. 2013).

The over dependence on the industrial manufactured material such as "cement" has often kept the cost of construction high, especially in developing countries. On the other hand, there has been intensified effort aimed at harnessing agricultural wastes for further usage. Thus, the possible use of agricultural waste such as groundnut shell will considerably reduce the cost of construction as well as reduce or eliminate the environmental hazards caused by such waste (Alabadan et al. 2006).

The pozollanic properties of GSA (Table 1) have made it a possible better replacement of industrial additives in soil stabilization and some other civil engineering works. Mahmoud et al. (2012) investigated the production of sandcrete blocks in Nigeria using GSA as cement replacement. They observed that the optimum replacement level was achieved at $20 \%$ GSA with a corresponding strength which fell within the recommended limit of the Nigerian Industrial Standard (NIS).

Nwofor and Sule (2012) investigated the use of GSA as partial replacement for cement in concrete production. The percentage replacement of Ordinary Portland Cement (OPC) varied to the control ( $0 \%$ replacement) about $40 \%$. They concluded that a percentage replacement of $10 \%$ GSA is suitable for sustainable construction, especially in mass concrete constructions.

Buari et al. (2013) studied the potentials of GSA as a partial replacement for ordinary Portland cement (OPC) in concrete. The partial replacement of OPC by GSA was varied from $0 \%$ to $20 \%$ in the concrete. The results showed that the OPC/GSA concrete of $10 \%$ replacement performed better in comparison to the acceptable standard. It was therefore concluded that this percentage would be more suitable for mass concrete production. 
Table 1: Composition of GSA (Mahmoud et. al. 2012)

\begin{tabular}{ll}
\hline Parameters & GSA Sample $(\%)$ \\
\hline $\mathrm{SiO}_{2}$ & 26.96 \\
$\mathrm{Al}_{2} \mathrm{O}_{3}$ & 5.82 \\
$\mathrm{Fe}_{2} \mathrm{O}_{3}$ & 0.5 \\
$\mathrm{CaO}$ & 9.5 \\
$\mathrm{MgO}$ & 5.6 \\
$\mathrm{SO}$ & 1.86 \\
$\mathrm{~K}_{2} \mathrm{O}$ & 20.02 \\
$\mathrm{Na}_{2} \mathrm{O}$ & 1.15 \\
$\mathrm{P}_{2} \mathrm{O}_{5}$ & 2 \\
$\mathrm{MnO}_{2}$ & 0.32 \\
$\mathrm{TiO}_{2}$ & 0.69 \\
$\mathrm{LOI}$ & 22 \\
\hline
\end{tabular}

Edeh et al. (2013) evaluated the characteristics of GSA-stabilized reclaimed asphalt pavements (RAP) with a view to determining its suitability for use as highway pavement material in flexible pavements construction. The results showed that the properties of RAP improved with GSA treatment. They concluded that $80 \%$ RAP $+20 \%$ GSA and $90 \%$ RAP $+10 \%$ GSA can be used as subgrade material in flexible pavements.

Adetoro and Dada (2015) used GSA to stabilise a selected soil sample from Ido - Ekiti, Ekiti State, Southwestern part of Nigeria. The GSA was added to the soil from $2 \%$ to $10 \%$ (by proportion of soil) in $2 \%$ increment. It was observed that, after stabilisation, the soil's maximum dry density (MDD) value decreased while the optimum moisture content (OMC) and California bearing ratio (CBR) values increased with increase in the GSA content. It was concluded that the stabilisation of the soil with GSA brought about the improvement of the mechanical strength of the soil.

Gajera and Thanki (2015) stabilised black cotton soils in Gujarat state using GSA. The results showed that there was a marginal increase in the soaked CBR. There was also a considerable increase in unconfined compressive strength (UCS) of the soil. It was concluded that addition of GSA resulted in the improvement of the strength of the soils.

Krishni and Beebi (2015) studied the effects of GSA and waste polypropylene fibers on the shear strength of unsaturated soil. GSA and polypropylene fiber were mixed with the soil at varying proportions. It was concluded from the obtained results that the GSA and polypropylene fiber reinforcement can be considered to be a good ground improvement technique, especially for engineering projects on weak soils.

Karthika and Muthukumar (2018) investigated the use of GSA as a stabilising agent for the improvement of the properties of soil. They added GSA from $2 \%$ to $12 \%$ at $2 \%$ increment to the soil while determining the soil index properties at each combination. It was observed that the optimum percentage of GSA for the improvement of soil properties was $6 \%$.

Review of existing and available literature on the pozzzolanic and stabilisation properties of GSA showed that the effect of the particle size of the GSA was not taken into consideration. This study therefore sought to investigate specifically the effect of GSA particle size passing BS $450 \mu \mathrm{m}$ sieve size on stabilisation of soil.

\section{Materials and methods}

\subsection{Materials and equipment}

The materials used for the study included: lateritic soil samples, obtained from two different locations in Osun State, Southwestern Nigeria; and groundnut shell ash (GSA). The following equipment and apparatus were used to carry out the laboratory experiments: Set of British Standard sieves; mechanical sieve shaker; chemical weighing balance; sensitive balance; drying oven; Cassagrande apparatus (for Atterberg limit tests); standard proctor mould and rammer (for compaction); and CBR machine.

\subsection{Methods}

\subsubsection{Soil sampling and preparation}

Two lateritic soil samples were obtained from: (i) a borrow pit located at Redeemers' University in Ede, Osun State, Southwestern Nigeria; and (ii) another borrow pit along Ife-Ibadan express way, Ile-Ife, Osun State, Southwestern Nigeria. One sample was collected from each location. The samples were collected at a depth of approximately $1 \mathrm{~m}$. They were collected using digger and shovel; the collected samples were neatly wrapped in nylon and immediately taken to the Geotechnical Engineering Laboratory of the Department of Civil Engineering, Obafemi Awolowo University, Ile-Ife for analyses. The natural moisture content was determined and the soil samples were then air-dried for subsequent analyses.

\subsubsection{Preparation of groundnut shell ash (GSA)}

Groundnut shell was obtained from waste disposed at Akinola market, Ipetumodu, Osun state; Shaki, Oyo State; and Obafemi Awolowo University, Ile-Ife, all in Southwestern part of Nigeria. The shells were washed free of any dirt or contaminant. They were dried in the open air for a b o u 72 hours. GSA was then obtained by burning the groundnut shells in a kiln at the Material Laboratory of the Department of Materials Science and Engineering, Obafemi Awolowo University, Ile-Ife. The burning was done at a regulated temperature of $550^{\circ} \mathrm{C}$; and the obtained ash was subsequently air-dried (ASTM 1994). After this, the GSA was sieved using British Standard size 425 $\mu \mathrm{m}$; the quantity passing was collected, stored in a tight polythene bag to avoid any form of hydration, and kept to be used for further laboratory tests and analyses.

\subsubsection{Preliminary and geotechnical tests on soil samples}

The following preliminary and geotechnical tests were conducted on soil samples in their natural states: natural moisture content determination; particle size analysis; specific gravity test; determination of Atterberg limits; compaction test; and determination of unsoaked CBR. 
The tests and analyses were conducted following standard procedures as outlined in BS 1377 (1990). The results obtained from the grain size distribution analysis and the Atterberg's limits tests were used to classify the soil samples.

\subsubsection{Stabilisation of soil with GSA}

The GSA was mixed with the soil samples in proportions of $2 \%, 4 \%$ and $6 \%$. The adopted quantity of GSA was first mixed with the airdried soil by hand, so that a fairly homogeneous mixture is obtained. GSA was mixed with soil samples by weight. For each proportion of GSA, the following tests were conducted on the resulting stabilized soils, following standard procedures as outlined in BS 1377 (1990): determination of Atterberg limits; compaction tests; and determination of unsoaked CBR. The results of the geotechnical tests on stabilised soils were compared with the results in the natural state of the soils. The results were compared and optimum proportion of GSA for soil stabilisation was determined.

\section{Results and discussion}

\subsection{Description of sampling points}

The Geographic Positioning System (GPS) location of the sampling point at Redeemers' University in Ede, Osun State is $7^{\circ} 40^{\prime} 51^{\prime \prime N}, 4^{\circ}$ $26^{\prime} 45^{\prime \prime E}$. The sample from this location was described as sample A. Also the GPS location of the sampling point along Ife-Ibadan express way, Ile-Ife, Osun State is 4²6’1617.68"N, $7^{\circ} 29^{\prime} 1792.72^{\prime \prime}$. The sample from this location was described as sample B.

\subsection{Results of preliminary and geotechnical tests on soils in their natural state}

The results of the preliminary and geotechnical tests on soils in their natural state are shown in Table 2. The lower the moisture content of soil the better. The two samples could be described as having fair quantity of moisture content, with sample A having a higher value. The specific gravity of most lateritic soils falls within the ranges of 2.65-2.85 (Lamber and Whiteman 1969). These values indicate that the degree of laterisation is high in the soil samples. According to Das (2006), a soil is said to be clayey if fine fractions (fractions passing sieve number 40) have a plasticity index greater than or equal to 11 . Therefore, samples A and B could be rightly described as clayey. From the results of sieve analyses and Atterberg limits tests, the two soil samples were found to belong to A-2-7 sub-group of AASHTO classification.

Wahab (1997) indicated that any lateritic soil having a liquid limit in excess of $30 \%$ and plasticity index above $12 \%$ should be rated poor for use under bituminous surfacing. However, Federal Ministry of Works and Housing (1997) specified a maximum liquid limit of $40 \%$ and a maximum plasticity index of $10 \%$ for a highway subgrade material. Obviously, the two natural soil samples did not meet the standard requirements for use as subgrade material. Thus, it was imperative to improve the soils.

Table 2: Preliminary and Geotechnical Tests Results of Soils in Their Natural States

\begin{tabular}{lll}
\hline Properties & Sample A & Sample B \\
\hline Natural moisture content (\%) & 26.7 & 21.8 \\
Specific gravity & 2.785 & 2.722 \\
Liquid limit (\%) & 59.69 & 52.83 \\
Plastic limit (\%) & 36.67 & 17.69 \\
Plastic index (\%) & 23.02 & 35.14 \\
$\%$ passing sieve No. 200 & 2.54 & 1.01 \\
Percentage passing sieve No. 40 & 36.04 & 17.17 \\
AASHTO Classification & $\mathrm{A}-2-7$ & $\mathrm{~A}-2-7$ \\
Maximum dry density $\left(\mathrm{kg} / \mathrm{m}^{3}\right)$ & 1341 & 1341 \\
Optimum moisture content $(\%)$ & 26.3 & 20.5 \\
Unsoaked CBR $(\%)$ & 7 & 2 \\
\hline
\end{tabular}

\subsection{Effect of GSA on the properties of soil}

\subsubsection{Atterberg limits}

Figs. 1 and 2 show the variation of Atterberg limits with the addition of GSA to the soils. For sample A (Figure 1), the plastic limit (PL) value decreased with the addition of GSA to the natural soil. The lowest value of PL was obtained at $4 \%$ GSA, after which the value increased at $6 \%$ but not up to the original value (at $0 \%$ ). Increase in the amount of fines is expected to increase the value of PL (Karthika and Muthukumar 2018); and since the value did not reach the original value at $6 \%$ GSA, the possibility is that at a higher value of GSA the PL value will surpass the original value. The liquid limit (LL) also decreased in value from the soils natural state (0\% GSA), having the lowest value at $2 \%$ GSA, and increasing at $4 \%$ and reducing slightly ay $6 \%$. The LL at $6 \%$ is still lower than the original LL value (at $0 \%$ GSA).

For sample B (Fig. 2), the introduction of GSA consistently kept the PL above the initial value (0\% GSA) with the highest value at $6 \%$ GSA. The increase in the amount of fines at this stage was sufficient to cause significant increase in the value of PL (Karthika and Muthukumar, 2018). At $6 \%$ GSA the LL has slight increase above the initial value (0\% GSA), although there was also a decrease at $4 \%$ GSA.

For the two soils, the addition of GSA to the soils caused a change in the values of PL and LL, which automatically led to change in the values of plasticity index (PI). For sample A, the value of PI reduced from $23.02 \%$ (at $0 \%$ GSA) to $13.55 \%$ at $6 \%$ GSA, although the lowest value $(9.31 \%$ ) was obtained at $2 \%$ GSA. For sample B, the value of PI reduced from $35.14 \%$ (at $0 \%$ GSA) to $2.54 \%$ at $6 \%$ GSA. The reduction in the values of PI of the soils is an indication that addition of GSA to the soil significantly led to the improvement of the soils' properties (Karthika and Muthukumar 2018). 


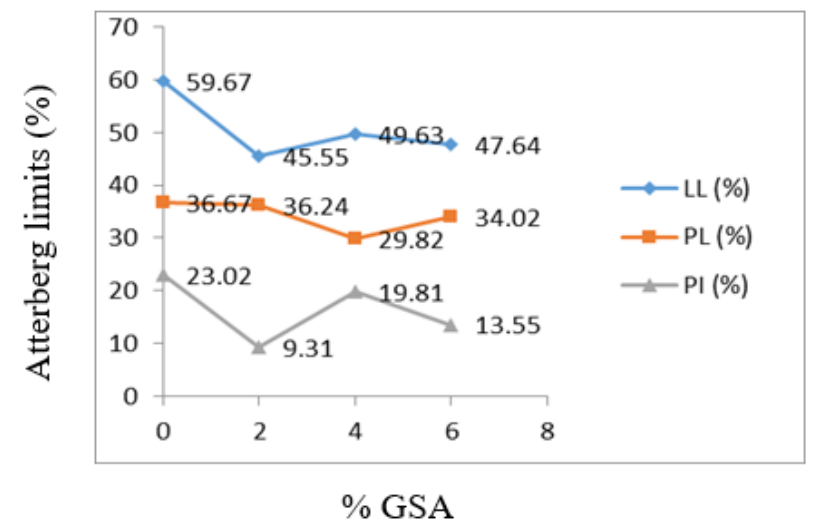

Fig. 1: Variation in Atterberg Limits with GSA Addition - Sample A.

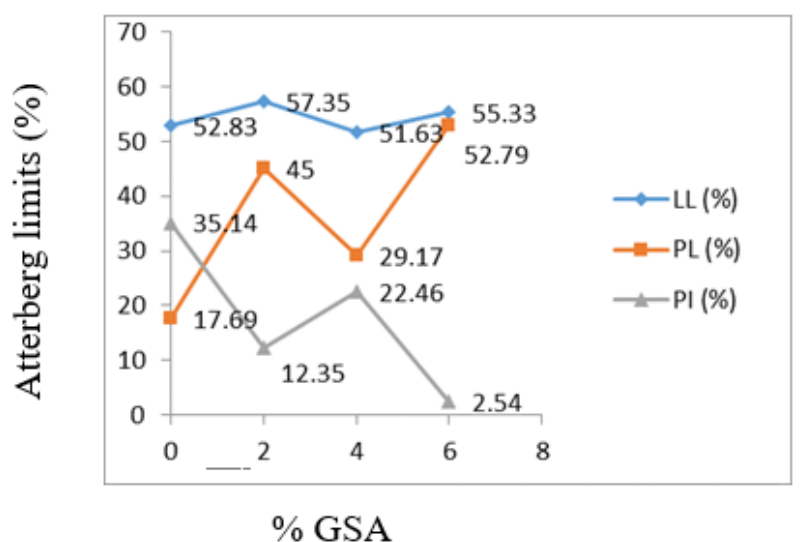

Fig. 2: Variation in Atterberg Limits with GSA Addition - Sample B.

\subsubsection{Compaction parameters}

Figs. 3 and 4 show the variation in OMC and MDD of the soils as GSA was added in proportion. It can be observed that the OMC value generally decreased with increase in the GSA content (Fig. 3). This can be attributed to the complete usage of all the water content during compaction, resulting in low hydration (Otoko and Precious 2014; Gajera and Thanki 2015). For the two soils, the initial increase in OMC may have been caused by an increasing demand for water by various cations and the clay mineral particles undergoing hydration reaction, as GSA is been added to the soil. The additive (GSA) decreased the quality of free silt, clay fraction and coarse minerals with the formation of large surface areas (Marks and Halliburton 1970; Osinubi 1997; Moses 2008).

The MDD values decreased with increase in the GSA content (Fig. 4), though there was an increase at $2 \%$ GSA for the two soils. This can be attributed to the replacement of soil by the GSA in the mixture which has relatively lower specific gravity compared to that of the soil. It could be as a result of coating of the soil by GSA which resulted in large particles with larger voids and density. The decrease in the MDD values may also be due to the flocculation and agglomeration leading to volumetric decrease in unit weight. It may be due to the presence of large, low density aggregate of particles, or as a result of the coarse aggregate voids being filled with groundnut shell ash particles (Ola 1983; Osula 1984; Medubi 1998; Osinubi 1998; Moses 2008; Otoko and Precious 2014; Adetoro and Dada 2015). The initial increase in the values of MDD up to $2 \%$ GSA could probably be attributed to the flocculation and agglomeration leading to volumetric decrease in unit weight (Medubi 1998).

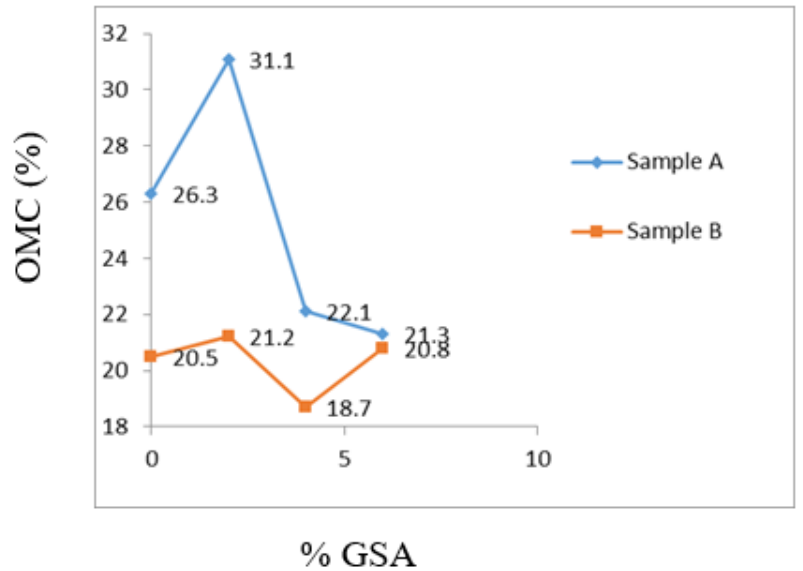

Fig. 3: Variation in OMC with GSA addition. 


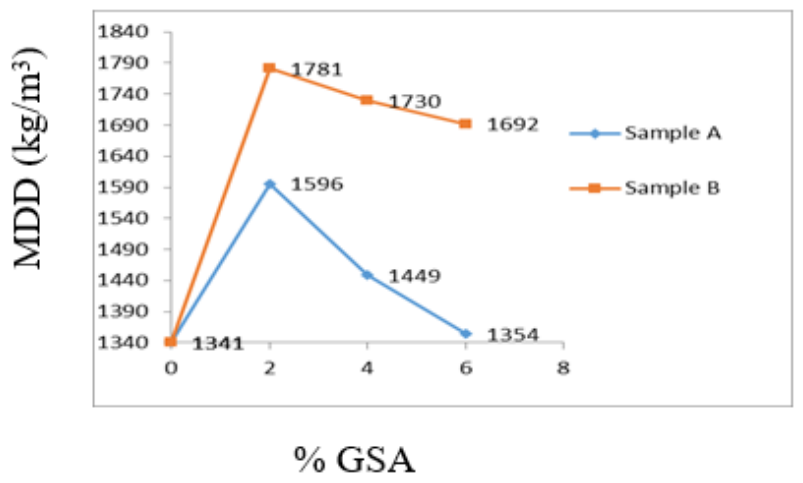

Fig. 4: Variation in MDD with GSA Addition.

\subsubsection{California bearing ratio (Unsoaked)}

Fig. 5 presents the variation of unsoaked CBR with increase in GSA content. For sample A, the CBR value initially increased up to the addition of $2 \%$ GSA before dropping; while for sample B, the value dropped up to $2 \%$ GSA, increased up to $4 \%$ GSA and remained constant between $4 \%$ and $6 \%$ GSA.. The initial decrease in the CBR value is due to the reduction in silt and clay content of the soil which reduced its cohesion. The increment in the CBR value could be attributed to gradual formation of cementious compound between the GSA and Calcium Hydroxide $\left(\mathrm{Ca}(\mathrm{OH})_{2}\right)$ present in the soil. The decrease in the CBR values could be due to non mobilisation of the GSA content in the reaction, thus occupying space in each soil sample. This leads to reduced bonding in the mixture (Adetoro and Dada 2015).

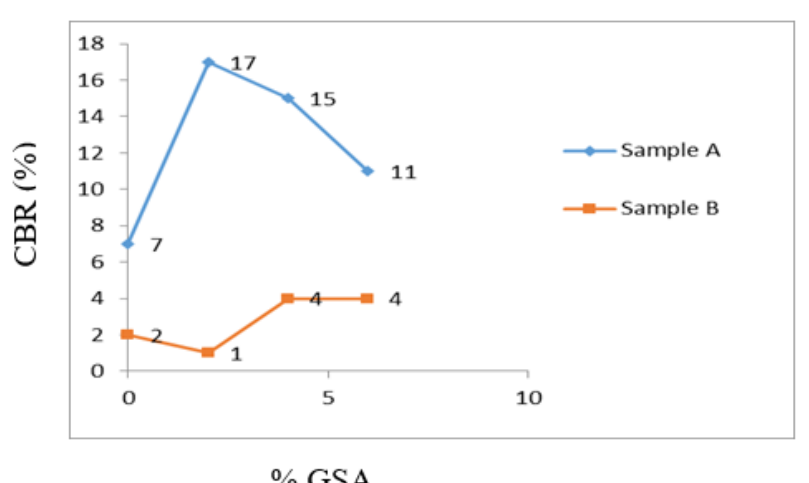

Fig. 5: Variation in CBR with GSA Addition.

\section{Conclusion}

The effect of GSA on soil stabilisation has been investigated. The two soil samples belong to A-2-7 subgroup of AASHTO classification. The results showed that addition of GSA (quantity passing $425 \mu \mathrm{m}$ BS sieve) improved the properties of the tested soils. The GSA also improved the compaction parameters of the soils. The results of the CBR tests showed that maximum value of CBR was obtained at $2 \%$ GSA (for sample A) and $4 \%$ GSA for sample B. therefore GSA could be used to improve the strength of soils. The results of the study are valid for the tested soils. Further works should be conducted on soils in other locations. Further works could also be undertaken to investigate the effect of GSA (content passing $425 \mu \mathrm{m} \mathrm{BS} \mathrm{sieve)} \mathrm{at} \mathrm{proportion} \mathrm{beyond} 6 \%$ GSA. The effect of GSA content (retained on 425 $\mu \mathrm{m}$ BS sieve) on soils could also be investigated.

\section{References}

[1] Adetoro AE \& Dada OM (2015) Potentials of groundnut shell ash for stabilization of Ekiti State soil. Nigeria Journal of Multidisciplinary Engineering Science and Technology 2(8), 2301-2304.

[2] Alabadan BA, Njoku CF \& Yusuf MO (2006) The Potentials of Groundnut Shell Ash as Concrete Admixture. Agricultural Engineering International: The CIGR e-journal, Manuscript BC 05 012, vol. VIII.

[3] ASTM (1994) Standard Test Methods for Sampling and Testing Fly Ash or Natural Pozzolans for Use in Portland-Cement Concrete. Annual Book of ASTM Standards 04(02), 10p. ASTM International, West Conshohocken, PA,

[4] BS 1377 (1990) Methods of Testing Soils for Civil Engineering Purposes. BSI Publications, 389 Chiswick High Road London W4 4AL.

[5] Buari TA, Ademola SA \& Ayegbokiki SF (2013) Characteristic strength of groundnut shell ash and ordinary Portland cement blended concrete in Nigeria. IOSR Journal of Engineering 3(7), 1-7. https://doi.org/10.9790/3021-03760107.

[6] Das BM (2006) Principles of Geotechnical Engineering, 6th ed. Thomson Limited, Canada.

[7] Edeh JE, Joel M \& Aburabul JM (2013) Groundnut shell ash stabilized reclaimed asphalt pavement as pavement material. Advanced Materials Research vol. 824, 3-11. https://doi.org/10.4028/www.scientific.net/AMR.824.3.

[8] Federal Ministry of Works and Housings (1997). Nigerian General Specification for Roads and Bridges, Abuja, Nigeria.

[9] Gajera NV \& Thanki KR (2015) Stabilisation analysis of black cotton soil by using groundnut shell ash. International Journal for Innovative Research in Science and Technology 2(1), 158-162.

[10] Ghafoori N \& Cai Y (1997) Laboratory investigation of pulverished coal combustion bottom ash as a fine aggregate in roller compacted concrete. Proceedings of the third Canment/ACI International Symposium of Advances in Concrete Technology, Auckland, New Zealand.

[11] Ghafoori N (2000) Large Scale Utilization of Illinois PCC Bottom Ash in Roadways and Parking Lots of a Youth, Sports, Safety Complex. International Symposium of Advances in Concrete Technology, Auckland, New Zealand.

[12] James J \& Rao SM (1986) Reactivity of rice husks ash. Cement and Concrete Research vol. 16, 296-302. https://doi.org/10.1016/0008$\underline{8846(86) 90104-3}$. 
[13] Karthika AP \& Muthukumar L (2018) Stabilisation of black cotton soil using groundnut shell ash. International Research Journal of Engineering and Technology 5(2), 488-492.

[14] Krishna TM \& Beebi SS (2015) Soil stabilization by groundnut shell ash and waste fiber material. International Journal of Innovations in Engineering and Technology 5(3), 52-57.

[15] Lambe TW \& Whiteman RV (1969) Soil Mechanics, Mohindar Singh Sejwal for Wiley Eastern Ltd, New Delhi.

[16] Mahmoud H, Belel ZA \& Nwakaire C (2012) Groundnut shell ash as a partial replacement of cement in sandcrete blocks production. International Journal of Development and Sustainability 1(3), 1026-1032.

[17] Marks BD \& Haliburton TA (1970) Effects of sodium chloride and sodium chloride-lime admixtures on cohesive Oklahoma soils. 49th Annual Meeting of the Highway Research Board.

[18] Medubi A (1998) Stabilization of Black Cotton Soil using Superphosphate Fertilizer Processing Residue as Admixture. Unpublished M.Sc. Thesis, Department of Civil Engineering, Ahmadu Bello University, Zaria.

[19] Moses G (2008) Stabilization of black cotton soil with ordinary Portland cement using bagasse ash as admixture. IRJI Journal of Research in Engineering 5(3), 107-115.

[20] Muntohar AS (1999) Behaviour of Engineering Properties on the Clay Blended with Lime-Rice Husk Ash. Research Report for Grant.

[21] Nwofor TC \& Sule S (2012) Stability of groundnut shell ash/ordinary Portland cement concrete in Nigeria. Advances in Applied Science Research, 2(3), 2283-2287.

[22] Ola SA (1983) The Geotechnical Properties of Black Cotton Soils of North Eastern Nigeria. In: SA Ola (Editor) Tropical Soils of Nigeria in Engineering Practice, A.A. Balkema, The Netherlands, Rotterdam, 155-171.

[23] Oriola F \& Moses G (2010) Groundnut shell ash stabilization of black cotton soil. Electronic Journal of Geotechnical Engineering 15 , 415 - 428.

[24] Osinubi KJ (1997) Soil stabilization using phosphatic waste. Proceedings of 4th Regional Conference on Geotechnical Engineering, GEOTROPIKA 97, Johor Bahru, Malaysia, 225 - 244.

[25] Osinubi KJ (1998) Influence of compactive efforts and compaction delays on lime treated soils. Journal of Transportation Engineering, ASCE 124(2), 149 - 155. https://doi.org/10.1061/(ASCE)0733-947X(1998)124:2(149)

[26] Osula DOA (1984) Cement Stabilization Using Hydrated Lime as an Admixture. Unpublished M.Sc. Thesis, Department of Civil Engineering, Ahmadu Bello University, Zaria.

[27] Otoko GR \& Precious K (2013) Stabilization of Nigerian deltaic clay (Chikoko) with groundnut shell ash. International Journal of Engineering and Technology Research 2(6), $1-11$

[28] Wahab KA (1997) Highway Geotechnical Properties of a Lateritic Soil along Ile-Ife - Ibadan Road, Southwest Nigeria. Unpublished B.Sc. Thesis, Department of Civil Engineering, Obafemi Awolowo University, Ile-Ife. 